\title{
GLOBAL TUBERCULOSIS BURDEN: IS NIGERIA LOSING THE WAR?
}

GT Jombo ${ }^{1}$, PT Mbaave ${ }^{2}$.

Department of Clinical Microbiology and Parasitology ${ }^{1}$ and Department of Medicine ${ }^{2}$, College of Health Science, Benue State University Teaching Hospital (BSUTH), Makurdi, Nigeria.

*Correspondence Author: GT Jombo, Professor of Clinical Microbiology and Parasitology College of Health Sciences, Benue State University, Makurdi, Nigeria

\begin{abstract}
Tuberculosis, an old disease has claimed several millions of lives over several thousands of years in the past and at present, is still a global disease. Although several countries of the world have put the disease under control in their own domain, the disease is still endemic in most parts of Asia and Africa who presently harbour over $70 \%$ of the total global burden of the disease. Nigeria presently records at least 320,000 new cases of TB every year and is the most endemic on the continent. With the increasing social instability in the country leading to the upsurge of internally displaced persons (IDPs), and establishment of several refugee camps, control of the disease has become more complicated. The ongoing TB control programme in the country should also specifically target the IDPs so as to avert a potential explosion of the disease with catastrophic consequence.
\end{abstract}

Keywords: Burden, Global, Nigeria, Tuberculosis.

The origin of TB among humans is deeply buried in antiquity and could be traced to as far back as the documented human existence. The archaeological and fossil findings from the ancient Chinese, Greek, Babylonian and Egyptian settings and dynasties all point to the probable existence of TB as far back as 25,000 BC. Hippocrates of Kos, of recent in 300 BC made vivid descriptions of a disease that could only be adjudged to be TB in modern day medicine. The causative agent of TB Mycobacterium tuberculosis was eventually isolated and identified by a German Physician Robert Koch in 1882. ${ }^{1}$

Globally there are over 8 million new infections of TB every year with at least 4000 deaths daily and 1.5 million deaths annually. This mortality exceeds the current HIV/AIDS related deaths which at present stands at 1.1 million annually. Majority (over 70\%) of the TB deaths are between Africa and Asia with India, Pakistan, China, Bangladesh, South Africa and Nigeria being the six countries with the highest burden of the disease. Africa with a population of 1.3 billion people accounts for $24 \%$ of the total global TB burden and Nigeria ranks number one as the country with the highest concentration of active TB cases in Africa. ${ }^{2-5}$

Nigeria presently records about 600,000 new TB cases per year with at least 200,000 deaths annually. At least 500,000 (90\%) of the infected persons have no access to proper laboratory diagnosis as well as proper medication. If this trend is left unchecked, it is projected that between 2015 and 2020, 4 million Nigerians will be infected with TB with a probable over one million deaths. It is generally estimated that for every hour 30 people die of TB in Nigeria. States with the highest burden of TB in the country include Kano, Kaduna, Katsina, Lagos, Oyo, Benue, Rivers and Akwa Ibom while Ekiti, Kwara, Jigawa and Abia are states with the lowest burden of active TB in the country. ${ }^{6-11}$

The effort by the national and states TB control programmes through advocacy, sensitization, public enlightenment, contact tracing, free testing and free drug treatment all appear not to have yielded the desired results. This is in addition to support from both foreign and local donor agencies in logistics, drugs, reagents, capacity building among others. The 
spread of the disease in the country at present appear to have defiled all the well mapped out control methods which have worked and put the disease under perfect control in other parts of the world. ${ }^{8,12}$

One question that would arise here is where and why are we getting it wrong? Has there been concrete sectoral analysis to ascertain the missing links in the execution of the TB control programme in the country? Have other climes with success stories in this regard been understudied to draw effective comparisons? These questions would challenge us to go back to the drawing board, troubleshoot and get back on track towards effective control of this epidemic.

Over the past half decade the upsurge of internally displaced persons (IDPs) due to civil unrest,

\section{References}

1. Mandal A. History of Tuberculosis, a review.http://www.hektoeninternational.org/

Schwartz_TB.htm

http://ajrccm.atsjournals.org/content/169/11/ 1181.long

http://www.heritage.nf.ca/society/tb_20th.ht $\underline{\mathrm{ml}}$.

2. GBD Tuberculosis Collaborators.The global burden of tuberculosis: results from the Global Burden of Disease Study 2015. Lancet Infect Dis. 2018; 18(3): 261-284.

3. World Health Organization (WHO). Global Tuberculosis Report. Geneva Switzerland. 2016: WHO/HTM/TB/2016.13.

4. Murray CJL, Styblo K, Rovillan A. Tuberculosis in developing countries: burdens, interventions and costs. Bull Intern Union Tubercul Lung Dis. 1990; 65: 6-24.

5. Ghere F, Otu J, Kendall L, Forson A, Kwara A, Kudzawu S, et al. The emerging threat of pre-extensively drug-resistant tuberculosis in West Africa: Preparing for large scale tuberculosis research and drug resistance surveillance. BMC Medicine. 2016; 14: e160.

6. Ebony AO, Ogwuche S, Ejeliogu EU, Agbaji OO, Shehu NY, Abah IO, et al. Prevalence of and risk factors for pulmonary tuberculosis among newly diagnosed HIV-1 insurgents and communal clashes has been on steady and alarming increase. These large congregations of people in IDP camps often with poor housing, sanitary, personal and environmental sanitation facilities constitute niches for TB to thrive and spread freely unhindered. This throws the entire Nigerian public at risk of infection and re-infection from TB Government needs to as a matter of urgency draw specific TB control protocol for the IDP camps scattered all over the country to permanently keep this disease at bay in those camps along with effective control of HIV/AIDS. This is to avert a greater disaster in the near future that may engulf the entire nation from explosion of a disease of which all the health institutions put together in the country may still be overwhelmed by it. ${ }^{12-13}$

infected Nigerian Children. Germs. 2016; 6(1): 21-28.

7. Jombo GTA, Akaakuma A, Kembe MM, Hembah-H SK. AIDS control in Benue state, north central Nigeria: challenges and prospects. American Journal of Research in Biology. 2013;1(1): 017-021.

8. National Agency for the control of AIDS (NACA). Federal Republic of Nigeria. Global AIDS response country progress report, Abuja, Nigeria 2015: GARPR.

9. Iliyasu Z, and Babashoni M, (2009). Prevalence of predictors of tuberculosis coinfection among HIV-seropositive patients attending the Aminu Kano teaching hospital, northern Nigeria. J Epidemiol. 2009; 19(2): 81-87.

10. Sani RA, Garba SA, Oyeleke SB, Abalaka ME. Prevalence of pulmonary tuberculosis (PTB) in Minna and Suleja Niger state, Nigeria. Am. J. of Medicine and Medical Sciences, 2015; 5(6): 287-291.

11. Abba PO, Jombo GT, Banjo AT, De-kaa PNL, Ojo BA. Pulmonary Tuberculosis in a general hospital in Ijebu-Ode city: Associated socio-demographic factors and implications for attainment of milleneum development goals in South-west Nigeria. Intern. J. of Biotechnology and Allied Fields. 2013;1(5): 257-270. 
12. Bisallah CI, Rampal L, Lye MS, Sidik SM, Ibrahim N, Iliyasu Z, Onyilo MO. Effectiveness of health education intervention in improving knowledge, attitude, and practices regarding Tuberculosis among HIV patients in General Hospital Minna, Nigeria - A randomized control trial. PLoS One. 2018; 13(2): e0192276.

13. Hassan AO, Olukolade R, Ogbuji QC, Afolabi S, Okwuonye LC, Kusimo OC, et al. Knowledge about Tuberculosis: A Precursor to Effective TB ControlFindings from a Follow-Up National KAP Study on Tuberculosis among Nigerians. Tuberc. Res. Treat. 2017; 2017: 6309092e. 